\title{
Correction to: The effects of regenerative injection therapy compared to corticosteroids for the treatment of lateral Epicondylitis: a systematic review and meta-analysis
}

Julie Barnett ${ }^{1,2^{*}}$, Madison N. Bernacki ${ }^{1}$, Jessica L. Kainer ${ }^{1}$, Hannah N. Smith ${ }^{1}$, Annette M. Zaharoff ${ }^{2}$ and Sandeep K. Subramanian ${ }^{1}$

Correction to: Arch Physiother (2019) 9:12 https://doi.org/10.1186/s40945-019-0063-6

In the original version of this article [1] the legends of Figs. 2 and 3 were inadvertently interchanged.

Figure 2 presents the results of meta-analyses examining the effectiveness of the corticosteroid injections compared to regenerative injections on pain using the VAS scale at 1 month (a), 2 months (b), 3 months (c) and 6 months (d) post-injection.

Figure 3 presents the risk of bias summary for included RCTs.

The figure legends have already been updated in the original article [1].

Published online: 27 January 2020

\section{Reference}

1. Barnett, et al. The effects of regenerative injection therapy compared to

corticosteroids for the treatment of lateral Epicondylitis: a systematic review and meta-analysis. Arch Physiother. 2019;9:12. https://doi.org/10.1186/ s40945-019-0063-6.

\footnotetext{
The original article can be found online at https://doi.org/10.1186/s40945019-0063-6

* Correspondence: barnettj3@uthscsa.edu

'Department of Physical Therapy, School of Health Professions, UT Health

San Antonio, 7703 Floyd Curl Drive, MSC 6247, San Antonio, TX 78229, USA

${ }^{2}$ The Non-Surgical Center of Texas, San Antonio, USA
}

(c) The Author(s). 2020 Open Access This article is distributed under the terms of the Creative Commons Attribution 4.0 International License (http://creativecommons.org/licenses/by/4.0/), which permits unrestricted use, distribution, and reproduction in any medium, provided you give appropriate credit to the original author(s) and the source, provide a link to the Creative Commons license, and indicate if changes were made. The Creative Commons Public Domain Dedication waiver (http://creativecommons.org/publicdomain/zero/1.0/) applies to the data made available in this article, unless otherwise stated. 